Kansas State University Libraries

New Prairie Press

Conference on Applied Statistics in Agriculture

1991 - 3rd Annual Conference Proceedings

\title{
MESSY EXPERIMENTAL DESIGNS
}

Dallas E. Johnson

Follow this and additional works at: https://newprairiepress.org/agstatconference

Part of the Agriculture Commons, and the Applied Statistics Commons

\section{(c) (i) $\ominus$}

This work is licensed under a Creative Commons Attribution-Noncommercial-No Derivative Works 4.0 License.

\section{Recommended Citation}

Johnson, Dallas E. (1991). "MESSY EXPERIMENTAL DESIGNS," Conference on Applied Statistics in Agriculture. https://doi.org/10.4148/2475-7772.1420

This is brought to you for free and open access by the Conferences at New Prairie Press. It has been accepted for inclusion in Conference on Applied Statistics in Agriculture by an authorized administrator of New Prairie Press. For more information, please contact cads@k-state.edu. 


\title{
MESSY EXPERIMENTAL DESIGNS
}

\author{
Dallas E. Johnson \\ Department of Statistics \\ Kansas State University \\ Manhattan, KS 66502
}

\begin{abstract}
This paper describes the statistical analysis of an agricultural experiment that was conducted in a very complex, but somewhat reasonable, experimental design. A correct analysis of data collected from the experimental design used requires the estimation of 8 error terms.
\end{abstract}

\section{Introduction}

An experiment was conducted to determine the effects of IRRigation, Previous Crop, and GYPsum on the yield of wheat. The plot plan is shown in Figure 1. The irrigation treatments are defined as DRAINED and UNDRAINED, the previous crops are: F-Fallow, P-Perennial Alfalfa, $\mathrm{R}$-Previous three year rotation (sesbania-wheat-sesbania), and $\mathrm{W}$-Wheat straw. Gypsum treatments are denoted by G+-Gypsum applied and G--No gypsum applied.

Note that the west side of the field was drained while the east side was not drained. The sides for the irrigation treatments were selected at random. The east-west rows were grouped into blocks of two rows each, and the gypsum treatments were randomly assigned to the rows within each block. It is not known whether this was done for convenience or whether there was a physical rationale for forming blocks of two rows each for the gypsum treatments. The previous crop treatments were assigned to pairs of rows and the columns of each half of the field. These were assigned in a latin square arrangement with previous crop treatments being rerandomized within each half of the field. The REP notation at the top of each column was provided by the researcher and is not useful for the analysis. One might suppose that the researcher expected that the columns of this plot plan would provide independent replicates of the IRRIGATION treatments. However, true replicates must come from random assignments of the irrigation treatments to the columns of the plot plan. The columns in this design are more accurately called subsamples and do not represent independent replications of the irrigation treatments.

Measurements were taken on each of the smallest sized plots giving a total of 64 measurements.

The questions about the fixed effects which are of interest are those that would be of interest in most 3 -way cross-classified treatment structure experiments. The fixed effects are: IRR, PC, GYP, IRR*PC, $I R R * G Y P, P C \star G Y P$, and $I R R * P C * G Y P$. How should data from this experiment be analyzed? This is the topic of this paper.

One way to answer this question is to consider each of the different sizes of experimental units to which factors have been randomly assigned. This experiment has 8 different sizes of experimental units. These are illustrated in Figures $2-9$ by shading a typical experimental unit of each type. The different sizes of experimental units are: 
(1) Half Plot - The irrigation treatments have been randomly assigned to these. There are two such experimental units. See Figure 2 .

(2) Row Pair - The row pairs are blocks for the gypsum treatments. The row pairs have been divided into two equal parts and the gypsum treatments have been randomly assigned to the halves in each block. The row pairs are also blocking factors for rows in a latin square design. Each of the previous crop treatments occur in pairs once within each row of each square. There are four such experimental units. See Figure 3.

(3) Column Block - The columns in each half plot are blocking factors for columns in a latin square design. Each of the previous crop treatments occur in pairs once within each column of each square. There are eight such experimental units. See Figure 4.

(4) Half Row Pair within Square - These are the experimental units for Row Pair*Irrigation effects. There are eight such experimental units. See Figure 5.

(5) Previous Crop - These experimental units consist of pairs of the smallest sized plots. The previous crop treatments have been randomly assigned to these in a latin square configuration with a new randomization for each square. There are 32 such experimental units. See Figure 6.

(6) Gypsum - These are the experimental units to which the Gypsum treatments have been randomly assigned. These units were blocked into row pairs, and the gypsum treatments were randomly assigned to one-half of each row pair. There are 8 such experimental units. See Figure 7.

(7) One-fourth row pair - These are the experimental units for the Irrigation*gypsum effects. There are 16 such experimental units. See Figure 8 .

(8) Smallest Plot - These are the smallest sized experimental units. These are the experimental units to which Irrigation* Crop*gypsum effects have been assigned. See Figure 9.

One way to see how such an experiment can be analyzed is to first consider each of the experimental unit sizes separately. Develop an analysis for each size, and then put all of the separate parts into one complete analysis. Analyses for each of the different sizes of experimental units are described in Sections 1-8, respectively.

\section{Half Plot Analysis}

There are only two half plots so there is only one contrast for measuring effects amongst the half plots. This single degree of freedom contrast measures the difference between the irrigation treatments. Unfortunately, this part of the experiment is not replicated; hence, there is no measure of experimental error for this experimental unit 
size and as a result, there is no legitimate statistical test for comparing the levels of irrigation treatments. The columns of the design used represent subsamples and not independent replications. The form of an AoV table for the half plot analysis is given in Table 1.

\section{Row Pair Analysis}

There are 4 row pairs, so there are 3 orthogonal contrasts for comparing row pairs. There is no information about fixed effects in these contrasts. These row pairs act as blocks for the gypsum treatments. The form of an AoV table for the row pair analys is is shown in Table 2 .

\section{Column Block Analysis}

There are 8 column blocks, so there are 7 orthogonal contrasts comparing column effects. One contrast in the column block effects measures the difference between irrigation treatments. This is the same contrast discussed in Section 1. Contrasts which are orthogonal to this one measure subsampling error rather than experimental error for the irrigation treatments. These contrasts contain no information about fixed effects, and it is not possible to further partition these contrasts into measures of different effects. The form of an Aov table for the column block analysis is shown in Table 3 .

\section{Half Row Pair within Square Analysis}

There are 8 half row pairs within each square, so there are 7 orthogonal contrasts comparing half row pairs. One such contrast measures the difference between irrigation treatments, 3 others are those described in Section 2 which measure differences in complete row pairs. The remaining 3 degrees of freedom come from interaction contrasts between complete row pairs and irrigation. These interaction contrasts contain no information about fixed effects. One could say that they measure experimental error for these sizes of experimental units, but this error is not appropriate for any comparisons of fixed effects. Thus I prefer to label it as IRR $\star R P$. The form of the AoV table for the half row pair within square analysis is shown in Table 4.

\section{Previous Crop Analysis}

There are 32 experimental units to which the previous crop treatments have been assigned, so there are 31 orthogonal contrasts measuring differences between these experimental unit sizes. Amongst these contrasts are: seven which measure column effects, which can be partitioned as shown in Section 3; three which measure row pair effects and three which measure row pairtirrigation interaction as described in Section 4; three which measure previous crop effects, and three which measure irrigation*previous crop interaction. The remaining 12 contrasts contain no information about fixed effects and thus provide measures of experimental error for comparing fixed effect contrasts in these same sizes of experimental units, namely the previous crop effect and irrigation*previous crop interaction effect. The form of the AoV 
table for the analysis of the previous crop experimental units is shown in Table 5 .

\section{Gypsum Analysis}

There are 8 experimental units to which the gypsum treatments have been assigned, so there are 7 orthogonal contrasts comparing these sizes of experimental units. Three of these compare row pairs as described in Section 2 and one compares the two gypsum treatments. The remaining 3 contrasts come from interaction contrasts of row pairs with gypsum and contain no information about fixed effects; these measure experimental error for these sizes of experimental units. The form of the Aov table for the analysis of the gypsum experimental units is shown in Table 6 .

\section{One-fourth Row Pair Analysis}

The one-fourth row pair experimental units are shown in Figure 8 . There are 16 such experimental units, so there are 15 orthogonal contrasts measuring differences between these sizes of experimental units. Seven of these measure the effects described in section 6 and one measures the irrigation effect described in section 1 . The remaining seven contrasts are formed from the interaction between these two sets of effects. One of these contrast measures irrigation*gypsum interaction, and three others measure IRR*RP interaction as described in Section 4. The remaining three contain no information about fixed effects and provide measures of experimental error for these experimental unit sizes The resulting error term is used to test for the irrigation*gypsum interaction effect. The form of the AoV table for the one-fourth row pair analysis is shown in Table 7.

\section{Smallest Plot Analysis}

There are 64 of the smallest sized plots, so there are 63 orthogonal contrasts for comparisons between these smallest sized experimental units. Amongst the 63 orthogonal contrasts are 31 which measure the effects described in Section 5 and 15 which measure the fixed effects described in section 7. Seven of these are common to both sections, thus there $63-31-15+7=24$ orthogonal contrasts remaining. Three of these measure the prior crop*gypsum interaction, three measure the Irrigation*prior crop*gypsum interaction, and the remaining 18 measure experimental error for these sizes of experimental units. The form of the AoV table for these smallest sized experimental units is shown in Table 8 .

\section{A SAS ${ }^{R}$ Analysis of the Experiment}

Now that an appropriate analysis for each of the differing sizes of the experimental units has been determined, the next question is: can the data be analyzed with existing statistical software?

Since the experiment is balanced and since all of the comparisons in Table 8 form orthogonal sets, it should be possible to obtain a computer analysis with a carefully selected model. In addition to modelling the fixed effects (IRR, $P C$, IRR*PC, GYP, IRR*GYP, $P C \star G Y P$, and IRR*PC*GYP), 
the model must include terms for the random effects blocking terms ( $R P$, $C B(I R R)$, and $I R R * R P)$. The model must also contain terms which will partition out estimates for each of the experimental error effects (Errors C, D, and $E$ ). The residual sum of squares from such a carefully selected model will provide an estimate of the remaining error term, Error $F$.

Note that the analysis must have random effects terms and/or error terms for each experimental unit size. This experiment has 8 different sizes of experimental units, so there should be 8 error and/or random terms in the model. A model for this experiment should have 3 random effects terms and 5 error terms. Unfortunately, for this experiment, Error A cannot be estimated, since there were no independent replications of the irrigation treatments. Thus this model will only have 7 such terms.

Actually, random effects terms are also error terms. So far they have not been identified as such, primarily because they are not used as denominators for any F-ratios corresponding to the fixed effects in the analysis. It is important to note that all error and random effects terms must be considered when estimating standard errors for fixed effect means and for comparisons amongst the fixed effects.

The data in this experiment can be analyzed with the GLM procedure of $\mathrm{SAS}^{\mathrm{R}}$ by using the following commands (the terms in bold face are random effects terms and/or error terms):

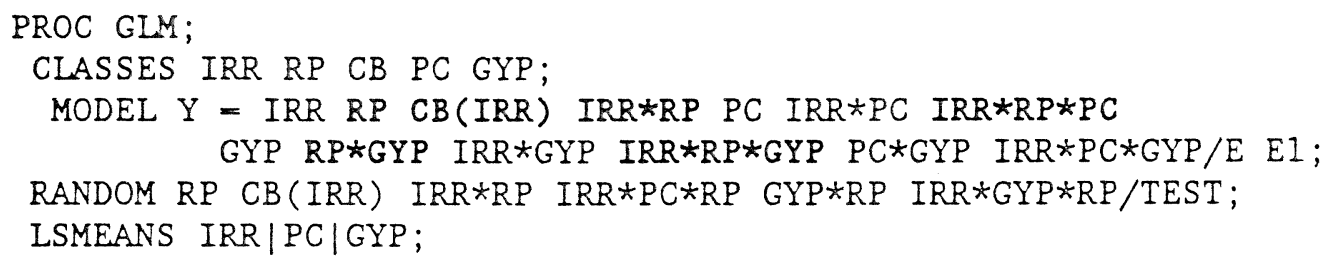

Errors C, D, and $E$ are estimated by the effects, IRR*RP*PC, $R P * G Y P$, and $I R R * R P * G Y P$, respectively. Error $F$ is estimated by the residual sum of squares.

The TYPE I analysis gives appropriate sums of squares for each of the effects, and this analysis tests the usual fixed effects hypotheses which are tested in balanced three-way experiments. To see this one can examine the results of the El option used on the MODEL statement. The El option shows the general form of the TYPE I estimable functions, and this general form identifies the functions of the fixed effect parameters being compared to zero by the TYPE I analysis (See Milliken and Johnson (1984), Chapter 10). By using the TEST option on the RANDOM statement above, $S_{A S}{ }^{R}$ will provide corrected F-statistics for each of the effects in the model using the methods proposed in Milliken and Johnson (1984, Chapter 28).

It might be noted that for many experiments the TYPE III and/or TYPE IV analyses can often be used when the TYPE I analysis cannot. For this experiment, however, the sum of squares for the CB(IRR) term is not computed correctly by the TYPE III and TYPE IV analyses which is why the TYPE I analysis should be used. The TYPE III and IV analyses give the $C B(I R R)$ sum of squares as zero with zero degrees of freedom. The reason for this is that the contrasts which measure this effect are contained 
within those that are required for the Previous Crop Analysis as described in Section 5.

The actual data for this experiment are not available. In order to illustrate an analysis of data from this kind of messy experiment, data were manufactured. For each of the 64 smallest cell sizes, a data point was generated from a standard normal distribution. The commands used to generate the data are:

DATA; INPUT IRR GYP CB PC RP @@; Y=RANNOR(12334759); CARDS;

$\begin{array}{llllllllllllllllllllllllllllll}1 & 1 & 1 & 1 & 1 & 1 & 2 & 1 & 1 & 1 & 1 & 1 & 1 & 2 & 2 & 1 & 2 & 1 & 2 & 2 & 1 & 1 & 1 & 3 & 3 & 1 & 2 & 1 & 3 & 3 \\ 1 & 1 & 1 & 4 & 4 & 1 & 2 & 1 & 4 & 4 & 1 & 1 & 2 & 2 & 1 & 1 & 2 & 2 & 2 & 1 & 1 & 1 & 2 & 3 & 2 & 1 & 2 & 2 & 3 & 2 \\ 1 & 1 & 2 & 4 & 3 & 1 & 2 & 2 & 4 & 3 & 1 & 1 & 2 & 1 & 4 & 1 & 2 & 2 & 1 & 4 & 1 & 1 & 3 & 3 & 1 & 1 & 2 & 3 & 3 & 1 \\ 1 & 1 & 3 & 4 & 2 & 1 & 2 & 3 & 4 & 2 & 1 & 1 & 3 & 1 & 3 & 1 & 2 & 3 & 1 & 3 & 1 & 1 & 3 & 2 & 4 & 1 & 2 & 3 & 2 & 4 \\ 1 & 1 & 4 & 4 & 1 & 1 & 2 & 4 & 4 & 1 & 1 & 1 & 4 & 1 & 2 & 1 & 2 & 4 & 1 & 2 & 1 & 1 & 4 & 2 & 3 & 1 & 2 & 4 & 2 & 3 \\ 1 & 1 & 4 & 3 & 4 & 1 & 2 & 4 & 3 & 4 & 2 & 1 & 5 & 4 & 1 & 2 & 2 & 5 & 4 & 1 & 2 & 1 & 5 & 2 & 2 & 2 & 2 & 5 & 2 & 2 \\ 2 & 1 & 5 & 1 & 3 & 2 & 2 & 5 & 1 & 3 & 2 & 1 & 5 & 3 & 4 & 2 & 2 & 5 & 3 & 4 & 2 & 1 & 6 & 3 & 1 & 2 & 2 & 6 & 3 & 1 \\ 2 & 1 & 6 & 1 & 2 & 2 & 2 & 6 & 1 & 2 & 2 & 1 & 6 & 2 & 3 & 2 & 2 & 6 & 2 & 3 & 2 & 1 & 6 & 4 & 4 & 2 & 2 & 6 & 4 & 4 \\ 2 & 1 & 7 & 1 & 1 & 2 & 2 & 7 & 1 & 1 & 2 & 1 & 7 & 4 & 2 & 2 & 2 & 7 & 4 & 2 & 2 & 1 & 7 & 3 & 3 & 2 & 2 & 7 & 3 & 3 \\ 2 & 1 & 7 & 2 & 4 & 2 & 2 & 7 & 2 & 4 & 2 & 1 & 8 & 2 & 1 & 2 & 2 & 8 & 2 & 1 & 2 & 1 & 8 & 3 & 2 & 2 & 2 & 8 & 3 & 2 \\ 2 & 1 & 8 & 4 & 3 & 2 & 2 & 8 & 4 & 3 & 2 & 1 & 8 & 1 & 4 & 2 & 2 & 8 & 1 & 4 & & & & & & & & & & \end{array}$

The TYPE I AOV table from a GLM analysis of this manufactured data is given in Table 9: All of the F-Values and their corresponding PValues would be wrong in a real data case except those corresponding to the $P C * G Y P$ and IRR*PC*GYP effects. The results from the RANDOM option are shown in Table 10, and some of the results from the TEST option are shown in Table 11.

At this point, we have illustrated the different sizes of experimental units, have shown how this information can be used to identify error terms for a statistical analysis, have shown an appropriate model for the experiment, and illustrated an AoV table. To effectively complete an analysis of such an experiment, one will also need to be able to make mean comparisons amongst the fixed effects as well as estimating fixed effect means and their standard errors. This can be done by generalizing the results in Milliken and Johnson to a multiple error term case. The basic ideas are illustrated in Section 10.

\section{Estimating Contrasts in Fixed Effects.}

This section illustrates the steps required for obtaining correct standard errors of linear functions of the fixed effects for the experiment considered in this paper. It should be pointed out that the LSMEANS option in a GLM analysis of this experiment provides correct least squares means, but their corresponding standard errors are usually wrong and p-values for pairwise comparisons are often wrong. A knowledgeable data analyst may be able to select $E$ - options on the LSMEANS options to get many of the comparisons carried out correctly, but it is not usually possible to get the computer to correctly carry out all comparisons which are likely to be of interest.

Let $\mu_{i j k}$ represent the expected response from irrigation treatment $i$, prior crop treatment $j$, and gypsum treatment $k$. To illustrate the 
methods required for correcting the computer analysis consider estimating the following differences in the fixed effects:

1) $\bar{\mu}_{.1} \cdot \bar{\mu}_{.2 .}$ : this compares two prior crop main effect means

2) $\bar{\mu}_{11} \cdot \bar{\mu}_{12}$ : this compares two prior crop means when IRR=1

3) $\bar{\mu}_{\ldots 1} \bar{\mu}_{. .2}$ : this compares two gypsum main effect means

4) $\bar{\mu}_{\cdot 11}-\bar{\mu}_{\cdot 12}$ : this compares two gypsum means when $\mathrm{PC}=1$

5) $\bar{\mu}_{.11} \bar{\mu}_{\cdot 21}$ : this compares two prior crop means when GYP=1

CONTRAST and ESTIMATE statements corresponding to these functions of the fixed effects parameters which can be used in the GLM analysis presented are given in Table 12. Table 13 gives the results of these CONTRAST and ESTIMATE options. The standard errors in Table 13 are usually computed incorrectly and as a result, the t-tests and their corresponding p-values are also incorrect. Likewise the F-tests and their p-values from the contrast options are also incorrectly computed. Nevertheless, the results in Table 13 are useful, because they provide the information required to allow a data analyst to compute corrected standard errors, t-tests, and p-values with a little effort.

To describe how things can be fixed for this experiment, let $M S_{i}$, $i=1,2, \ldots, 7$, denote the observed mean squares for the random effects and error terms in the TYPE I AoV table. Thus $\mathrm{MS}_{1}=1.9899, \mathrm{MS}_{2}=1.7088$, $\mathrm{MS}_{3}=0.5750, \mathrm{MS}_{4}=1.7517, \mathrm{MS}_{5}=3.0866, \mathrm{MS}_{6}=0.2257$, and $\mathrm{MS}_{7}=1.4026$. Next one determines estimates of the individual variance components by solving the equations formed by setting the expected values of the error mean squares to their observed values. To illustrate, the equations which must be solved are:

$$
\begin{aligned}
& \hat{\sigma}_{\epsilon}^{2}+4 \hat{\sigma}_{I R G}^{2}+8 \hat{\sigma}_{\mathrm{RG}}^{2}+2 \hat{\sigma}_{\mathrm{IRP}}^{2}+8 \hat{\sigma}_{\mathrm{IR}}^{2}+16 \hat{\sigma}_{\mathrm{RP}}^{2} \quad-\mathrm{MS}_{1}, \\
& \hat{\sigma}_{\epsilon}^{2}+2 \hat{\sigma}_{\mathrm{IRP}}^{2}+\hat{\sigma o}_{\mathrm{C}(\mathrm{I})}^{2}=\mathrm{MS}_{2}, \\
& \hat{\sigma}_{\epsilon}^{2}+4 \hat{\sigma}^{2} \mathrm{IRG}+2 \hat{\sigma}_{\mathrm{IRP}}^{2}+8 \hat{\sigma}_{\mathrm{IR}}^{2}=\mathrm{MS}_{3} \text {, } \\
& \hat{\sigma}_{\epsilon}^{2}+2 \hat{\sigma}_{\text {IRP }}^{2}=\mathrm{MS}_{4} \text {, } \\
& \hat{\sigma}_{\epsilon}^{2}+4 \hat{\sigma}_{\mathrm{IRG}}^{2}+8 \hat{\sigma}_{\mathrm{RG}}^{2} \quad=\mathrm{MS}_{5} \text {, } \\
& \hat{\sigma}_{\epsilon}^{2}+4 \hat{\sigma}_{\text {IRG }}^{2} \quad=\mathrm{MS}_{6} \text {, and } \\
& \hat{\sigma}_{\epsilon}^{2} \quad-\mathrm{MS}_{7} . \\
& \begin{array}{l}
\hat{\sigma}_{\epsilon}^{2}=M S_{7}, \hat{\sigma}_{I R G}^{2}=\left(M_{6}-M S_{7}\right) / 4, \hat{\sigma}_{R G}^{2}=\left(M S_{5}-M S_{6}\right) / 8, \hat{\sigma}_{I R P}^{2}=\left(M S_{4}-M S_{7}\right) / 2, \\
\hat{\sigma}_{I R}^{2}=\left(M_{3}-M_{4}-M_{6}+M S_{7}\right) / 8, \sigma_{C(I)}^{2}=\left(M S_{2}-M S_{4}\right) / 8, \text { and }
\end{array}
\end{aligned}
$$




$$
\hat{\sigma}_{\mathrm{RP}}^{2}=\left(\mathrm{MS}_{1}-\mathrm{MS}_{3}-\mathrm{MS}_{5}+\mathrm{MS} \mathrm{S}_{6}\right) / 16 \text {. }
$$

Next it is noted that the standard error of any linear function of the fixed effect cell means will have the form $\left[k\left(\sigma_{\epsilon}^{2}+c_{1} \sigma_{I R G}^{2}+c_{2} \sigma_{R G}^{2}+c_{3} \sigma_{I R P}^{2}+c_{4} \sigma_{I R}^{2}+c_{5} \sigma_{R P}^{2}+c_{6} \sigma_{C(I)}^{2}\right]^{1 / 2}\right.$.

The values of $c_{1}{ }^{-c_{6}}$ can be obtained from the expected contrast mean squares given in Table 13, and the value of $k$ can be obtained as $k=$ $(\mathrm{PSE}){ }^{2} / \sigma_{\epsilon}^{2}$ where PSE is the printed standard error in Table 13 . Then the estimated standard error of a linear function of the fixed effects parameters can be obtained by computing $\left[k\left(\hat{\sigma}_{\epsilon}^{2}+c_{1} \hat{\sigma}_{\mathrm{IRG}}^{2}+c_{2} \hat{\sigma}_{\mathrm{RG}}^{2}+c_{3} \hat{\sigma}_{\mathrm{IRP}}^{2}+c_{4} \hat{\sigma}_{\mathrm{IR}}^{2}+c_{5} \hat{\sigma}_{\mathrm{RP}}^{2}+c_{6} \hat{\sigma}_{\mathrm{C}(\mathrm{I})}^{2}\right]^{1 / 2}\right.$.

The estimates of our contrasts and their corrected standard errors are given in Table 14.

To complete the analysis one has to be able to assign p-values to pseudo t-statistics formed by taking ratios of the estimates and their corresponding corrected standard errors. To do this, degrees of freedom are assigned to the t-tests by using satterthwaite's Theorem for approximating the distribution of a linear combination of independent chi-square random variables. To illustrate, consider the fourth contrast. From Table 13, the expected mean square of this contrast is $\sigma_{\epsilon}^{2}+4 \sigma_{I R G}^{2}+4 \sigma_{R G}^{2}$. Its estimate is equal to $.125\left(\mathrm{MS}_{5}\right)+.875\left(\mathrm{MS}_{6}\right)$. From Satterthwaite's Theorem, the approximate degrees of freedom to assign to this linear function of $\mathrm{MS}_{5}$ and $\mathrm{MS}_{6}$ is $\hat{\nu}=\frac{\left[.125 \mathrm{MS}_{5}+.875 \mathrm{MS}_{6}\right]^{2}}{(.125)^{2} \mathrm{MS}_{5}^{2} / \nu_{5}+(.875)^{2} \mathrm{MS}_{6}^{2} / \nu_{6}}$ where $\nu_{5}$ and $\nu_{6}$ are the degrees of freedom associated with $\mathrm{MS}_{5}$ and $\mathrm{MS}_{6}$, respectively. For the example

$$
\hat{\nu}=\frac{[.125(3.0866)+.875(0.2257)]^{2}}{\left.(.125)^{2}(3.0866)^{2} / 3+(.875)^{2}(0.2257)\right\}_{3}}=\frac{.5833^{2}}{.0626}=5.4 \text {, }
$$

$t=-0.0563 / 0.2700=-0.2085$, and the resulting $p$-value is 0.5785 . In a similar manner the degrees of freedom and approximate p-values can be obtained for the other contrasts. The results are given in Table 14 .

\section{REFERENCES}

Milliken, G.A. and Johnson, D.E. (1984). Analysis of Messy Data, Vol. 1 - Designied Experiments. New York: Van Nostrand Reinhold.

SAS Institute Inc. SAS ${ }^{R} /$ STAT User's Guide: Statistics, Release 6.03 Edition. Cary, NC: SAS Institute Inc., 1988. 
DRAINED

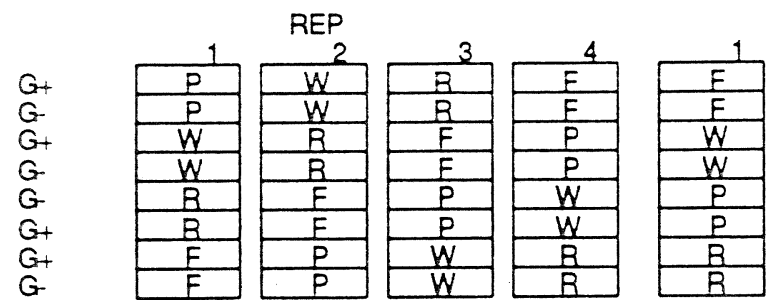

Figure 1. Plot plan for a 3-factor cross-classified experiment.
UNDRAINED

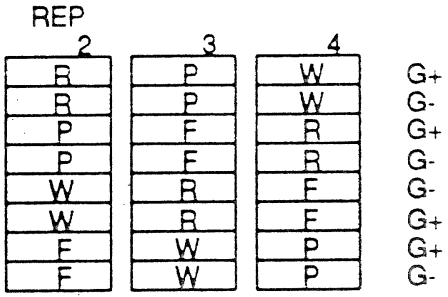

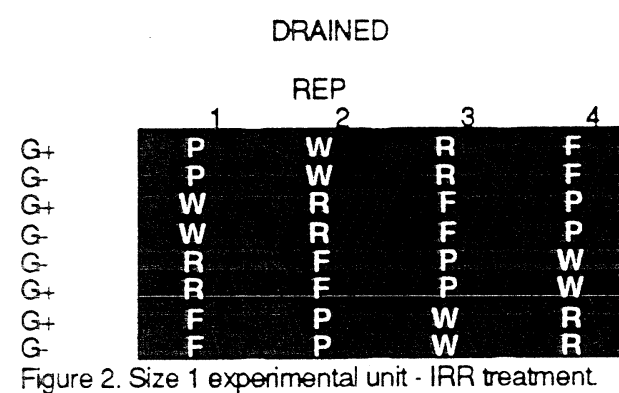

DRAINED

Figure 2. Size 1 experimental unit - IRR treatment
UNDRAINED

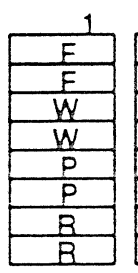
REP

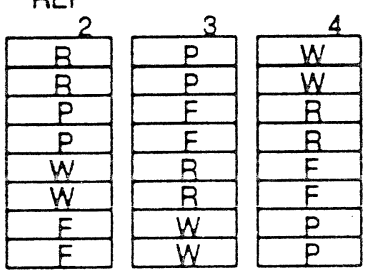

G+

$G_{+}$

G.

G+

$\mathrm{G}^{+}$

REP

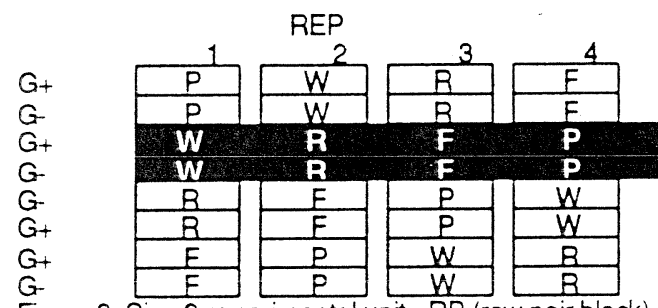

Figure 3. Size 2 experimental unit - RP (row pair blodk).

DRAINED

UNDRAINED
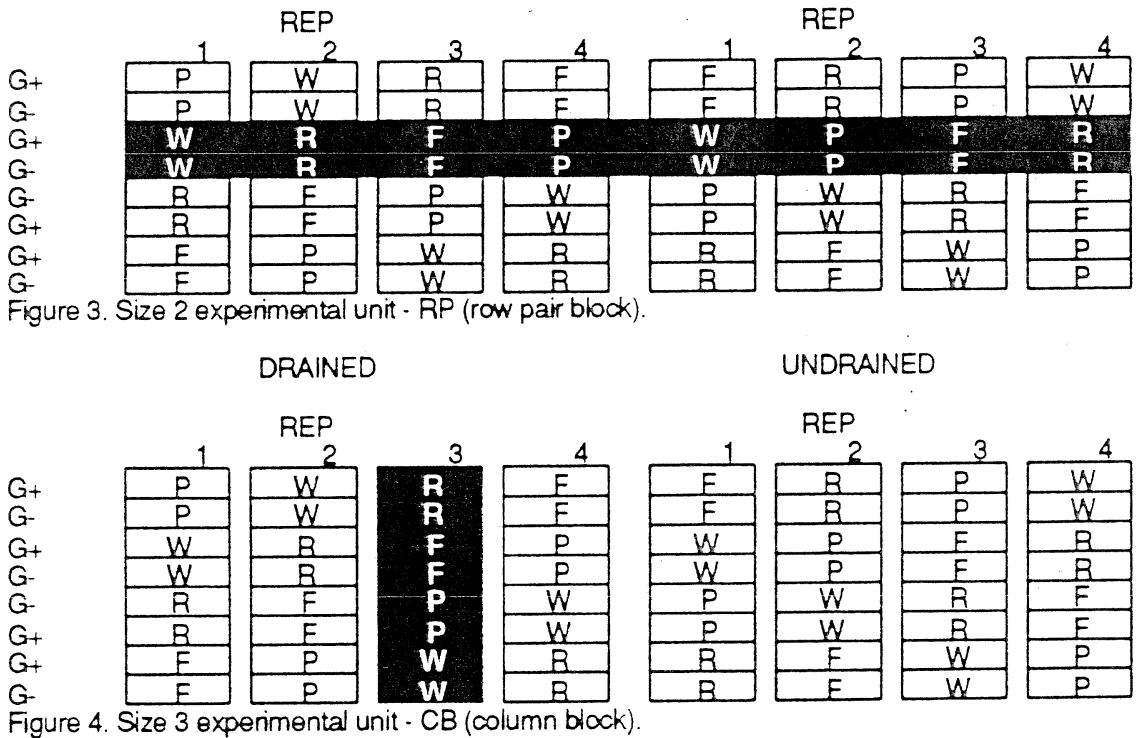

$\mathrm{G}_{+}$

$\mathrm{G}_{+}$

G-

G.

$\mathrm{G}+$

G+

Figure 4. Size 3 experimental unit - $C B$ (column block).

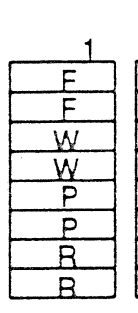

UNDRAINED

DRAINED

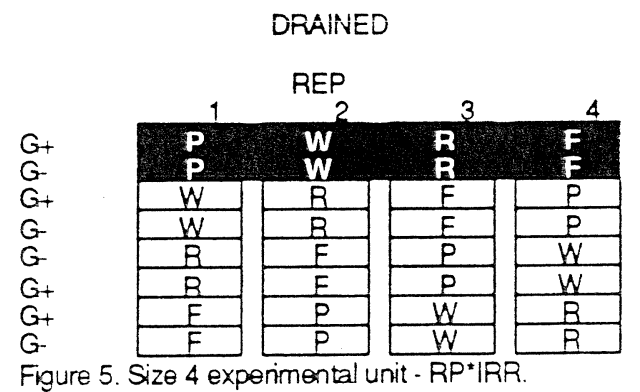

Figure 5. Size 4 experimental unit - RP*|RR
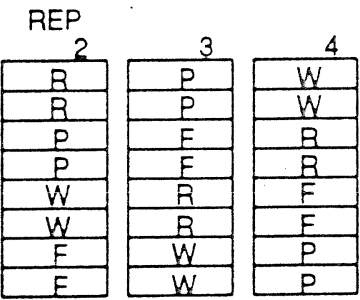

$G_{+}$

$G_{+}$

$G-$

$G$ -

$G_{+}$

G.

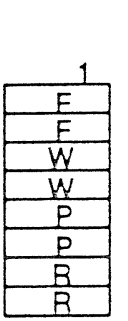

UNDRAINED

REP

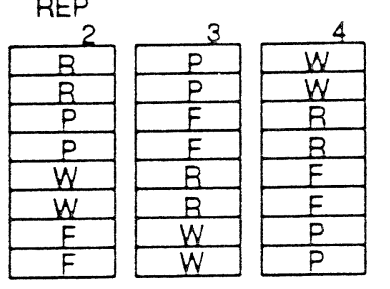

$G_{+}$
$G_{-}^{-}$
$G_{+}$
$G_{-}$
$G_{-}$
$G_{+}$
$G_{+}$
$G_{-}$ 
DRAINED

UNDRAINED
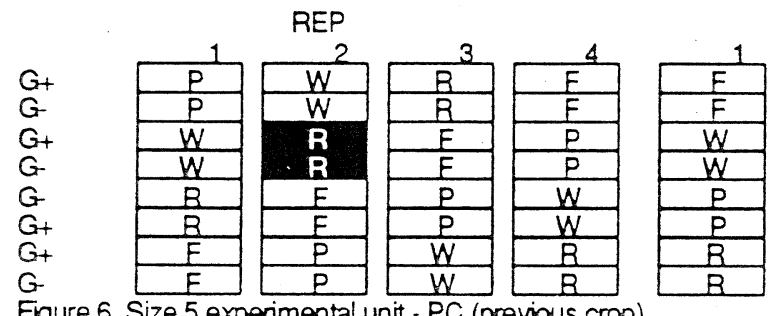

REP
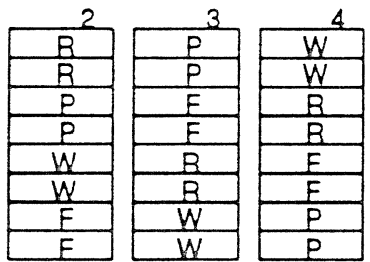

$\mathrm{G}_{+}$

$G_{+}$

G-

G+

$\mathrm{G}_{+}$

Figure 6. Size 5 experimental unit - PC (previous crop).

DRAINED

UNDRAINED

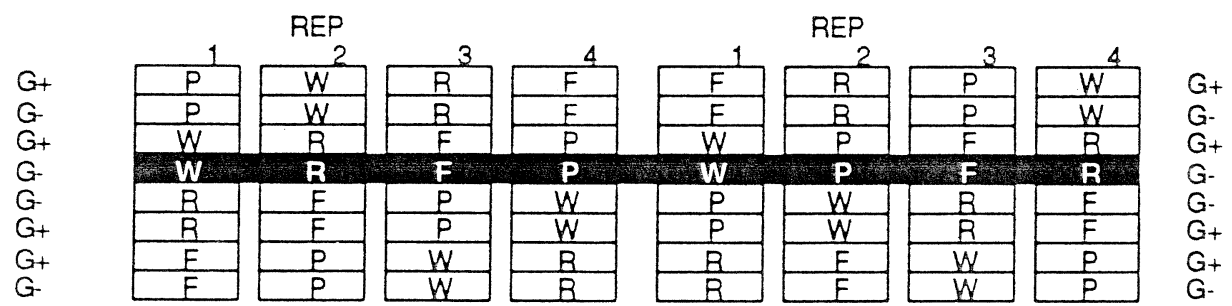

Figure 7. Size 6 experimental unit - GYP (gypsom treatment).

DRAINED

REP

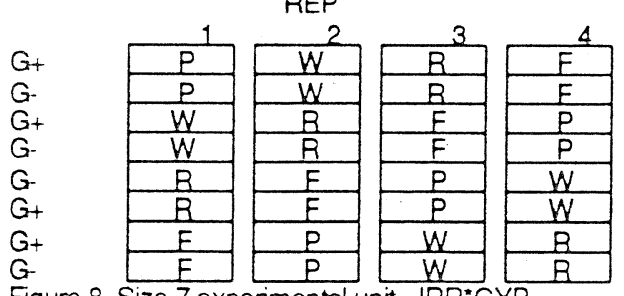

Figure 8. Size 7 experimental unit - IRR*GYP.

DRAINED

REP

Figure 9. Size 8 experimental unit - IRR*PC*GYP.

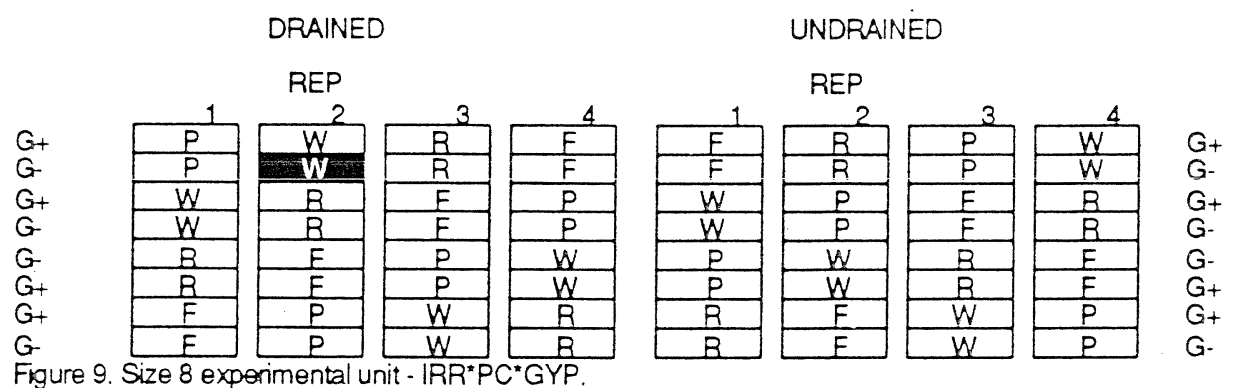

UNDRAINED

REP

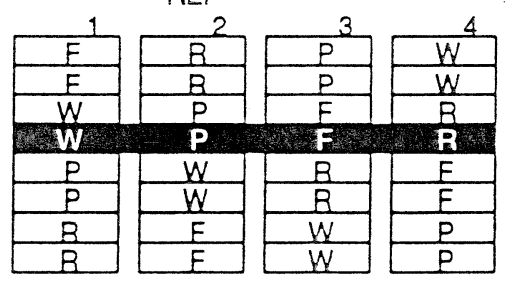

$G_{+}$

G-

G+

G-

$G_{+}$

G+ 
Table 1. AoV for the Half Plot Analysis.

\begin{tabular}{lc} 
Source & df \\
\hline IRR & 1 \\
Error A & 0 \\
\hline
\end{tabular}

Table 2. AOV for the Row Pair Analysis.

\begin{tabular}{lc} 
Source & df \\
\hline RP & 3 \\
\hline
\end{tabular}

Table 3. Aov for the Column Block Analysis.

\begin{tabular}{lc} 
Source & df \\
\hline IRR & 1 \\
Error A & 0 \\
CB (IRR) & 6 \\
\hline
\end{tabular}

Table 4. Aov for the Half Row Pair within Square Analysis.

\begin{tabular}{lc} 
Source & df \\
\hline IRR & 1 \\
Error A & 0 \\
RP & 3 \\
IRR $\star R P$ & 3 \\
\hline
\end{tabular}

Table 5. AoV for the Previous Crop analysis.

\begin{tabular}{lc} 
Source & df \\
\hline IRR & 1 \\
Error A & 0 \\
CB(IRR) & 6 \\
\hline & \\
$R P$ & 3 \\
IRR*RP & 3 \\
PC & 3 \\
IRR $* P C$ & 3 \\
Error C & 12 \\
\hline
\end{tabular}

Table 6. AoV for the Gypsum analysis.

\begin{tabular}{lc} 
Source & df \\
\hline RP & 3 \\
GYP & 1 \\
Error D & 3 \\
\hline
\end{tabular}


Table 7. Aov for the One-fourth Row Pair Analysis.

\begin{tabular}{lc} 
Source & df \\
\hline IRR & 1 \\
Error A & 0 \\
RP & 3 \\
IRR $\star R P$ & 3 \\
GYP & \\
Error D & 1 \\
\hline & 3 \\
IRR GYP & 1 \\
Error E & 3 \\
\hline
\end{tabular}

Table 8. Aov for the Smallest Sized Experimental Units.

\begin{tabular}{lr} 
Source & df \\
\hline IRR & 1 \\
Error A & 0 \\
CB (IRR) & 6 \\
RP & 3 \\
IRR $* R P$ & 3 \\
PC & 3 \\
IRR $* P C$ & 3 \\
Error C & 12 \\
GYP & 1 \\
Error D & 3 \\
IRR $* G Y P$ & \\
Error E & 1 \\
PC $* G Y P$ & 3 \\
IRR $* P C \star G Y P$ & \\
Error F & 3 \\
& 3 \\
\hline
\end{tabular}


Table 9. TYPE I AOV from GIM.

\begin{tabular}{|c|c|c|c|c|c|}
\hline \multirow{2}{*}{ Source } & 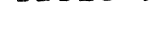 & \multirow{2}{*}{$\begin{array}{l}\text { Sum of } \\
\text { Squares }\end{array}$} & Mean & & \multirow[b]{2}{*}{$\operatorname{Pr}>F$} \\
\hline & $D F$ & & Square & E Value & \\
\hline Model & 45 & 68.46703683 & 1.52148971 & 1.08 & 0.4417 \\
\hline Error & 18 & 25.24615400 & 1.40256411 & & \\
\hline \multirow[t]{3}{*}{ Corrected Total } & 63 & 93.71319083 & & & \\
\hline & quare & C.V. & Root MSE & & Y Mean \\
\hline & 30602 & 1631.140 & 1.184299 & & 0.072606 \\
\hline Source & $\mathrm{DF}$ & Type I SS & Mean Square & F Value & $\operatorname{Pr}>E$ \\
\hline IRR & 1 & 0.69916919 & 0.69916919 & 0.50 & 0.4892 \\
\hline $\mathrm{RP}$ & 3 & 5.96976122 & 1.98992041 & 1.42 & 0.2700 \\
\hline$C B(I R R)$ & 6 & 10.25263401 & 1.70877234 & 1.22 & 0.3422 \\
\hline$I R R * R P$ & 3 & 1.72509224 & 0.57503075 & 0.41 & 0.7478 \\
\hline $\mathrm{PC}$ & 3 & 3.72119063 & 1.24039688 & 0.88 & 0.4679 \\
\hline$I R R * P C$ & 3 & 1.36406611 & 0.45468870 & 0.32 & 0.8078 \\
\hline$I R R * R P * P C$ & 12 & 21.02049815 & 1.75170818 & 1.25 & 0.3253 \\
\hline GYP & 1 & 0.51506547 & 0.51506547 & 0.37 & 0.5521 \\
\hline$R P \star G Y P$ & 3 & 9.25975536 & 3.08658512 & 2.20 & 0.1232 \\
\hline$I R R * G Y P$ & 1 & 0.24236915 & 0.24236915 & 0.17 & 0.6825 \\
\hline$I R R * R P * G Y P$ & 3 & 0.67722329 & 0.22574110 & 0.16 & 0.9212 \\
\hline$P C \star G Y P$ & 3 & 4.05700782 & 1.35233594 & 0.96 & 0.4311 \\
\hline IRR *PC*GYP & 3 & 8.96320418 & 2.98773473 & 2.13 & 0.1320 \\
\hline
\end{tabular}


Table 10. Expected Kean Squares of the Effects in the Type I Analysis.

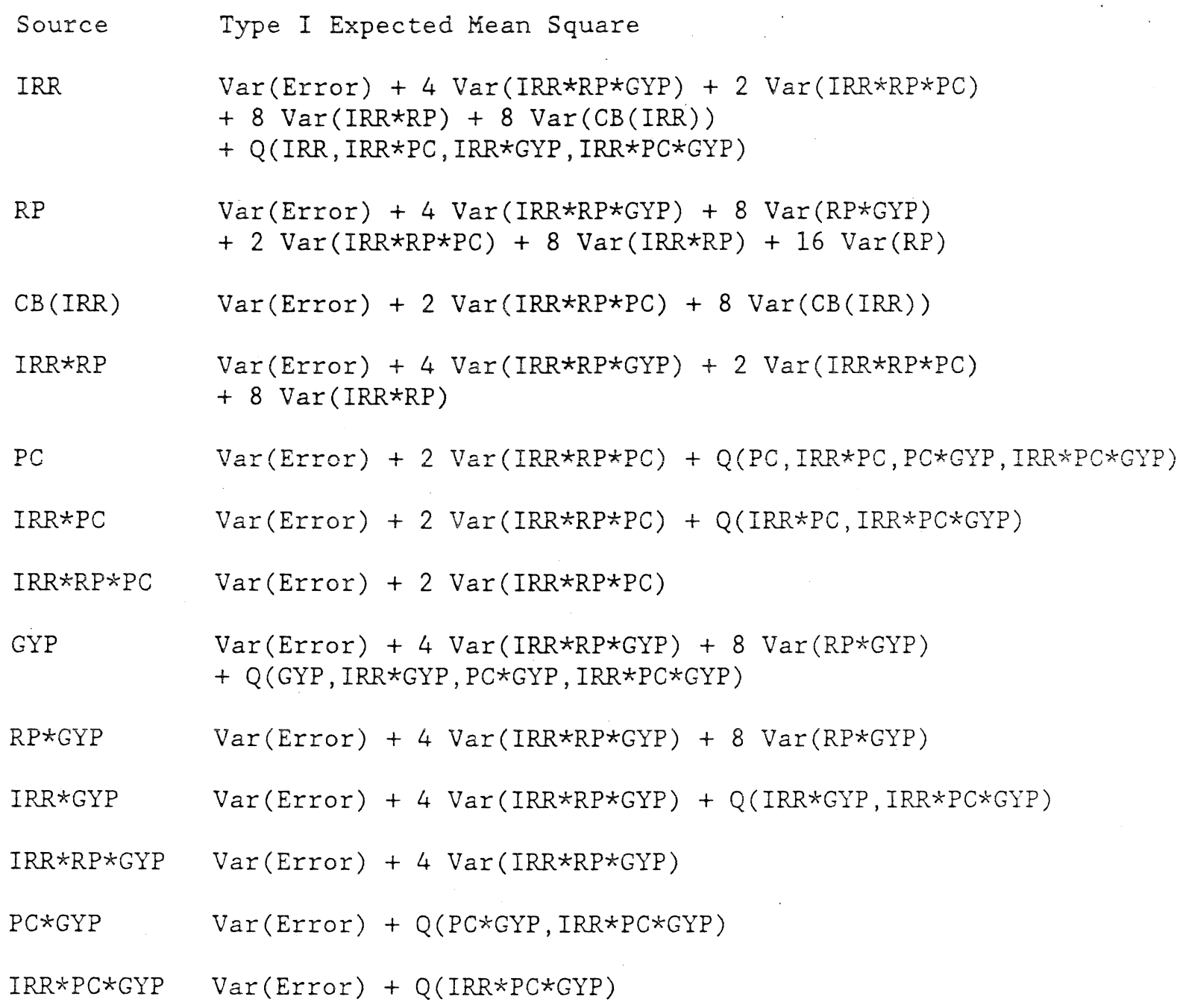


Table 11. Some of the Corrected F-tests from the TEST option.

General Linear Models Procedure

Tests of Hypotheses for Mixed Model Analysis of Variance

Dependent Variable: Y

Source: $\operatorname{IRR}$ *

Error: $M S(C B(I R R))+M S(I R R \star R P)-M S(I R R \star R P \star P C)$

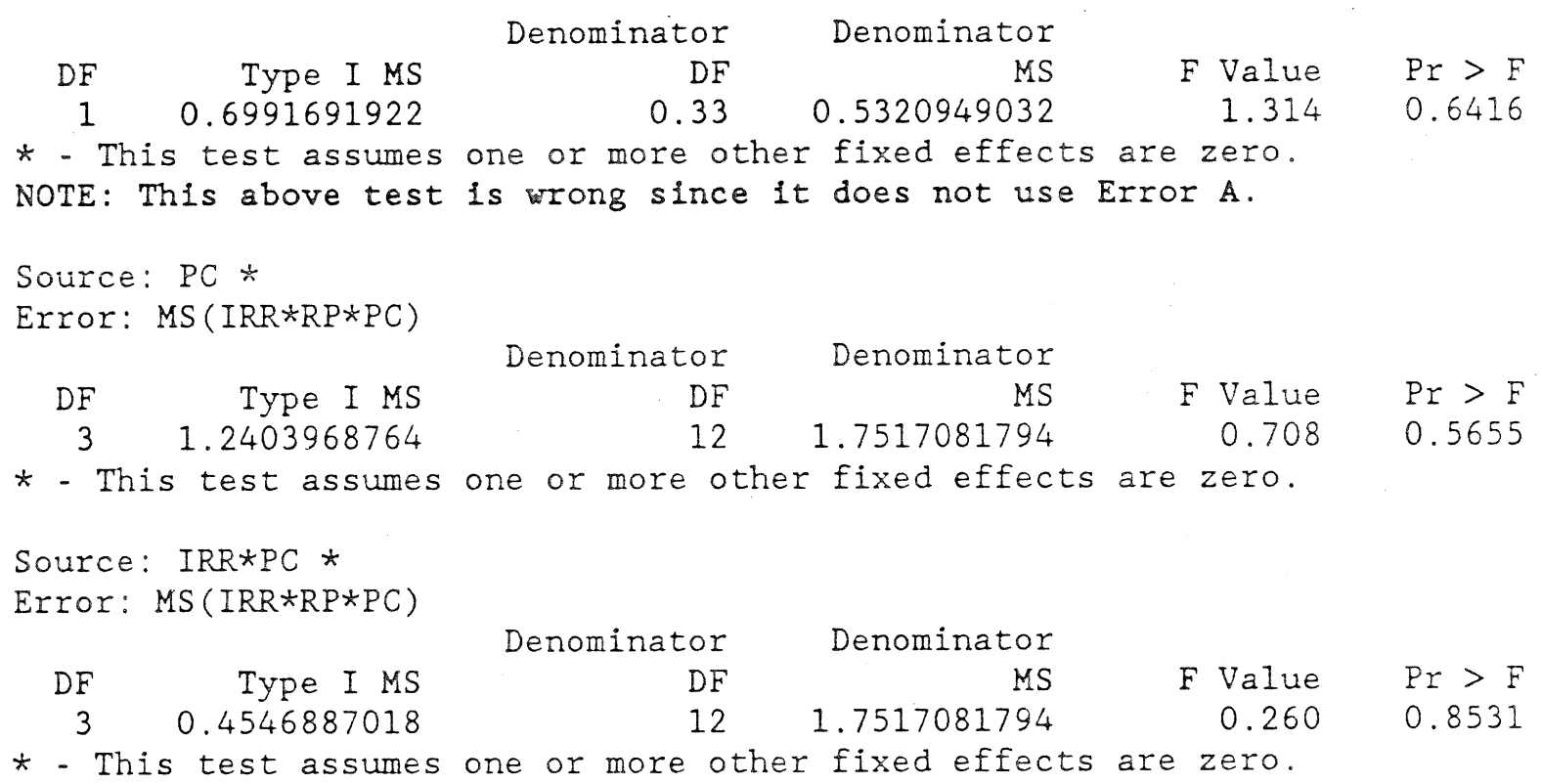

Source: GYP *

Error: $M S(R P * G Y P)$

\begin{tabular}{cccccc}
\multicolumn{5}{c}{ Denominator } & Denominator \\
DF & Type I MS & DF & MS & F Value & Pr $>F$ \\
1 & 0.5150654698 & 3 & 3.0865851197 & 0.167 & 0.7103
\end{tabular}

* - This test assumes one or more other fixed effects are zero.

Source: IRR*GYP *

Error: $M S(I R R \star R P \star G Y P)$

\begin{tabular}{rrrrrr}
\multicolumn{7}{c}{ Denominator } & Denominator \\
DF & Type I MS & DF & MS & $F$ Value & Pr $>F$ \\
1 & 0.242369155 & 3 & 0.2257410966 & 1.074 & 0.3763
\end{tabular}

* - This test assumes one or more other fixed effects are zero. 
Table 12. Contrast and Estimate options for GLM.

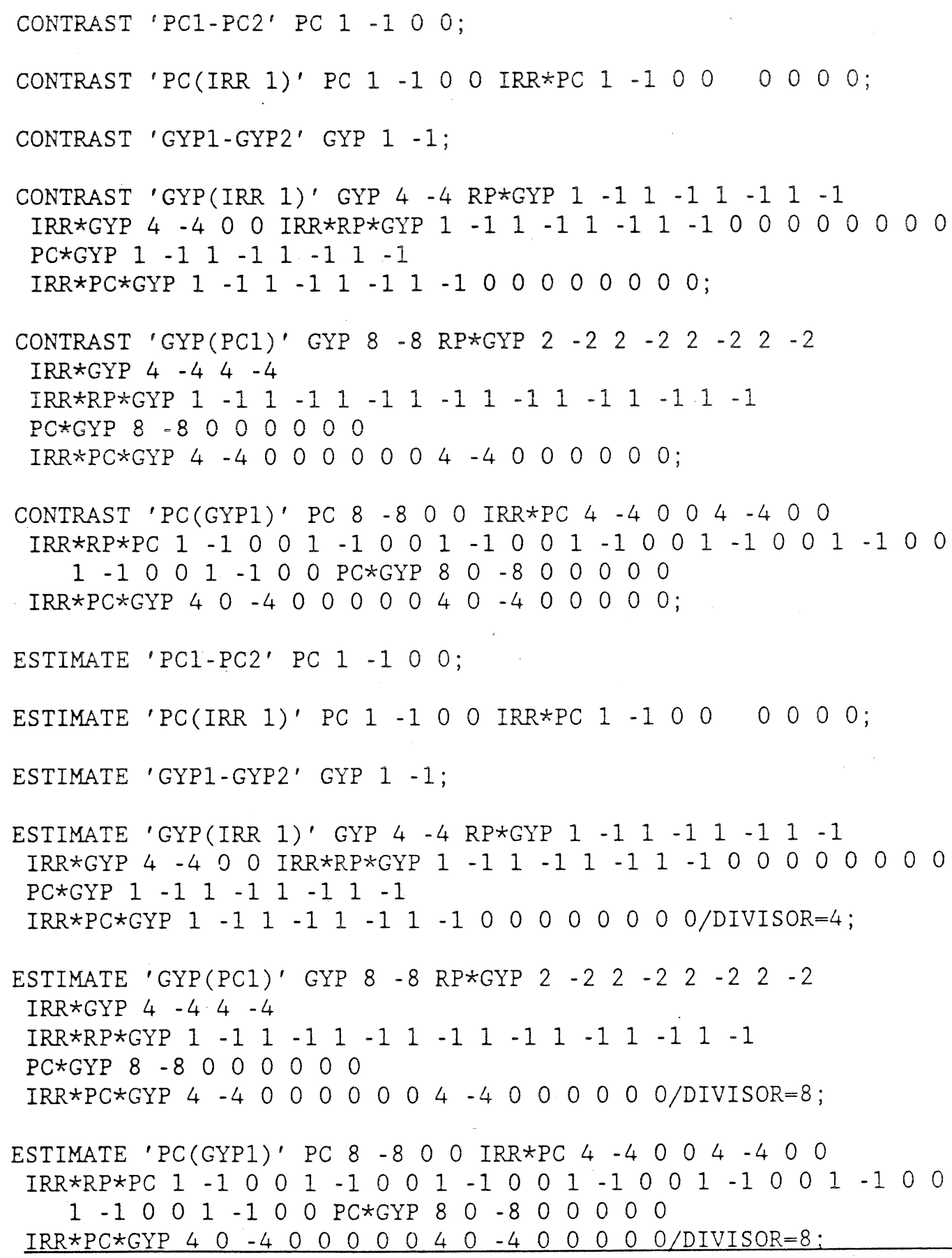


Table 13. Results from Contrast and Estimate Options.

\begin{tabular}{|c|c|c|c|c|}
\hline Contrast & \multicolumn{4}{|c|}{ Contrast Expected Mean Square } \\
\hline $\mathrm{PCl}-\mathrm{PC} 2$ & \multicolumn{4}{|c|}{$\begin{array}{l}\operatorname{Var}(\text { Error })+2 \operatorname{Var}(I R R \star R P \star P C) \\
+Q(P C, I R R \star P C, P C \star G Y P, I R R * P C * G Y P)\end{array}$} \\
\hline$P C(\operatorname{IRR} 1)$ & \multicolumn{4}{|c|}{$\begin{array}{l}\operatorname{Var}(\text { Error })+2 \operatorname{Var}(I R R * R P * P C) \\
+Q(P C, I R R * P C, P C * G Y P, I R R * P C * G Y P)\end{array}$} \\
\hline GYP1 - GYP2 & \multicolumn{4}{|c|}{$\begin{array}{l}\operatorname{Var}(\text { Error })+4 \operatorname{Var}(I R R * R P * G Y P)+8 \operatorname{Var}(R P * G Y P) \\
+Q(G Y P, I R R * G Y P, P C * G Y P, I R R * P C * G Y P)\end{array}$} \\
\hline GYP(IRR 1) & \multicolumn{4}{|c|}{$\begin{array}{l}\operatorname{Var}(\text { Error })+4 \operatorname{Var}(I R R * R P \star G Y P)+4 \operatorname{Var}(R P * G Y P) \\
+Q(G Y P, I R R * G Y P, P C * G Y P, I R R * P C * G Y P)\end{array}$} \\
\hline GYP (PCl) & \multicolumn{4}{|c|}{$\begin{array}{l}\operatorname{Var}(\text { Error })+\operatorname{Var}(I R R * R P * G Y P)+2 \operatorname{Var}(R P * G Y P) \\
+Q(G Y P, I R R * G Y P, P C * G Y P, I R R * P C * G Y P)\end{array}$} \\
\hline$P C(G Y P 1)$ & \multicolumn{4}{|c|}{$\begin{array}{l}\operatorname{Var}(\text { Error })+\operatorname{Var}(I R R * R P * P C) \\
+Q(P C, I R R * P C, P C * G Y P, I R R * P C * G Y P)\end{array}$} \\
\hline & & $\mathrm{T}$ for $\mathrm{HO}$ : & $r>|T|$ & Std Error of \\
\hline Parameter & Estimate & Parameter $=0$ & & Estimate \\
\hline PC1 - PC2 & 0.34316390 & 0.82 & 0.4232 & 0.41871293 \\
\hline$P C(\operatorname{IRR} 1)$ & 0.75042384 & 1.27 & 0.2212 & 0.59214950 \\
\hline GYP1 - GYP2 & -0.17942015 & -0.61 & 0.5521 & 0.29607475 \\
\hline GYP (IRR 1) & -0.05634265 & -0.13 & 0.8945 & 0.41871293 \\
\hline GYP (PC1) & -0.28286897 & -0.48 & 0.6386 & 0.59214950 \\
\hline$P C(G Y P 1)$ & 0.50929944 & 0.86 & 0.4011 & 0.59214950 \\
\hline
\end{tabular}

Table 14. Estimates and their Standard Errors.

\begin{tabular}{|c|c|c|c|c|c|}
\hline $\begin{array}{l}\text { Parameter } \\
\text { Function }\end{array}$ & Estimate & $\mathrm{k}$ & $\begin{array}{l}\text { Corrected } \\
\text { Standard } \\
\text { Error of } \\
\text { Estimate } \\
\end{array}$ & $\begin{array}{c}\text { pseudo } \\
t\end{array}$ & $\begin{array}{l}\text { Estimated } \\
\text { Degrees of } \\
\text { Freedom }\end{array}$ \\
\hline $\mathrm{PC1}-\mathrm{PC} 2$ & 0.3432 & .125 & 0.4679 & $0.734^{*}$ & $12^{*}$ \\
\hline$P C(I R R$ 1) & 0.7504 & .25 & 0.6618 & 1.134 & 12 \\
\hline GYP1-GYP2 & -0.1794 & .0625 & 0.4392 & -0.408 & 3 \\
\hline $\operatorname{GYP}(\operatorname{IRR} 1)$ & -0.0563 & .125 & 0.2700 & -0.209 & 5.4 \\
\hline GYP (PC1) & -0.2829 & .25 & 0.6752 & -0.419 & 12.8 \\
\hline$P C(G Y P 1)$ & 0.5093 & .25 & 0.5264 & 0.811 & 19.7 \\
\hline
\end{tabular}

